
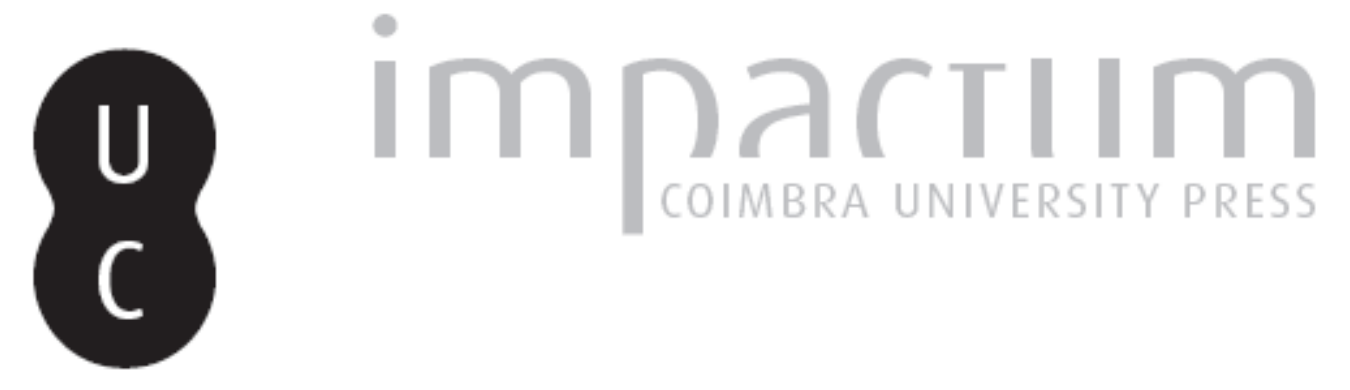

Nova visita de estudo do Instituto Oriental ao Egipto (Páscoa de 2009)

Autor(es): $\quad$ Araújo, Luís Manuel

Publicado por: Centro de História da Universidade de Lisboa

URL persistente:

URI:http://hdl.handle.net/10316.2/23794

DOI:

DOI:http://dx.doi.org/10.14195/0871-9527_19_17

Accessed : $\quad$ 26-Apr-2023 11:24:13

A navegação consulta e descarregamento dos títulos inseridos nas Bibliotecas Digitais UC Digitalis, UC Pombalina e UC Impactum, pressupõem a aceitação plena e sem reservas dos Termos e Condições de Uso destas Bibliotecas Digitais, disponíveis em https://digitalis.uc.pt/pt-pt/termos.

Conforme exposto nos referidos Termos e Condições de Uso, o descarregamento de títulos de acesso restrito requer uma licença válida de autorização devendo o utilizador aceder ao(s) documento(s) a partir de um endereço de IP da instituição detentora da supramencionada licença.

Ao utilizador é apenas permitido o descarregamento para uso pessoal, pelo que o emprego do(s) título(s) descarregado(s) para outro fim, designadamente comercial, carece de autorização do respetivo autor ou editor da obra.

Na medida em que todas as obras da UC Digitalis se encontram protegidas pelo Código do Direito de Autor e Direitos Conexos e demais legislação aplicável, toda a cópia, parcial ou total, deste documento, nos casos em que é legalmente admitida, deverá conter ou fazer-se acompanhar por este aviso. 

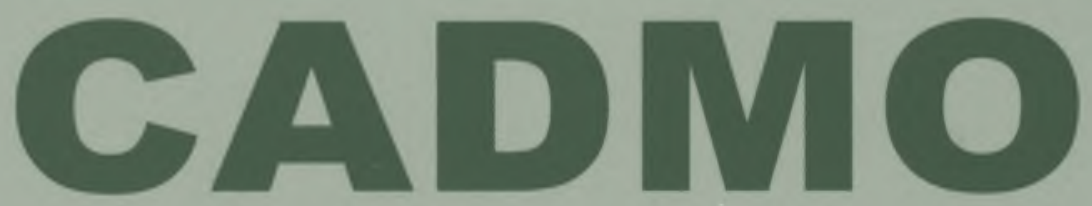

Revista de História Antiga

\author{
Centro de História \\ da Universidade de Lisboa
}

19

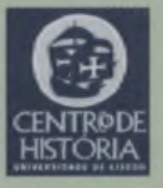

430 =

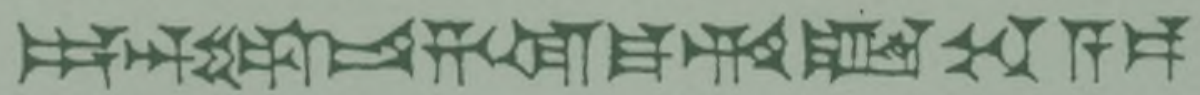

MHNIN AEI $\Delta$ E $\Theta E A ~ \Pi H \Lambda H I A \triangle E \Omega$ 


\section{NOVA VISITA DE ESTUDO DO INSTITUTO ORIENTAL AO EGIPTO (PÁSCOA DE 2009)}

A exemplo de anos anteriores, o Instituto Oriental da Faculdade de Letras da Universidade de Lisboa levou a efeito mais uma visita de estudo ao Egipto, que decorreu de 4 a 15 de Abril de 2009, aproveitando a pausa lectiva da Páscoa. A aliciante diferença em relação aos anos anteriores consistia no facto de o programa ser mais desenvolvido e, por isso mesmo, ter de englobar mais dias, porque o grupo se deslocou a Abido e a Dendera, ambas a norte de Lucsor, e a Kalabcha, perto da ilha de Filae-Agilkia, importantes zonas históricas que habitualmente não se incluem nos "pacotes" turísticos clássicos, mas que se justificava plenamente numa visita de estudo como esta.

A partida teve lugar em Lisboa a 4 de Abril, e no dia seguinte já estavam os viajantes no incontornável planalto de Guiza para admirar as grandes pirâmides da IV dinastia que lá se erguem, feitas para Khufu, Khafré e Menkauré, junto com a famosa Esfinge. Ao lado deste impressionante monumento leonino, que petrifica a majestade do poder da realeza egípcia, foi visitado o templo baixo de Khafré, também designado por templo de acolhimento, que era a etapa inicial do complexo funerário que ia deste precípuo lugar até à pirâmide e construções adjacentes (actualmente muito arruinadas), seguindo pelo caminho processional lajeado, hoje em grande parte desaparecido. Neste sítio histórico de Guiza puderam os visitantes, e em especial os alunos de História, ver ao vivo os monumentos que nas suas aulas de Arte Pré-Clássica e de Introdução à Egiptologia são estudados.

De tarde foi a visita ao Museu Egípcio do Cairo, onde foram admiradas as obras de arte lá expostas, com relevo para o percurso habitual que vai desde as salas dedicadas ao Império Antigo e ao Império Médio às do Império Novo, com justificada demora na sala que preserva os vestígios de Amarna-Akhetaton. Seguiu-se, no primeiro andar, a área ocupada pelo valioso espólio de Tânis (XXI dinastia) e de Tutankhamon (XVIII dinastia). E, uma vez mais, não puderam os 
visitantes deixar de lamentar o estado muito decrépito de algumas vitrinas, as legendas ultrapassadas, as teias de aranha, a sujidade e, em certos casos, o amontoado caótico e mesmo desleixado das peças em certas vitrinas.

O dia 6 foi dedicado à vasta necrópole de Sakara, com o tradicional trajecto iniciado no complexo funerário de Netjerikhet Djoser (III dinastia), cujas ingentes obras de reconstrução ainda prosseguem, continuando o trabalho pioneiro do notável egiptólogo francês Jean-Philippe Lauer no século passado. Ali mereceram demorada observação os edifícios do pátio do Heb-sed, a importante cerimónia mágico-litúrgica que iria permitir o rejuvenescimento do monarca, o pátio das capelas do Norte e do Sul, e a pequena capela situada na face do monumento virada para norte. Depois foi visitada a pirâmide de Teti (VI dinastia), que exibe nas paredes interiores os famosos «Textos das Pirâmides", após o que se entrou na grande mastaba de Mereruka, ali mesmo ao lado, para se apreciar a qualidade de um túmulo de um alto funcionário desse período histórico. Mais para leste, uma outra notável mastaba, a de Ptah-hotep, mereceu também o devido interesse. Muito mais há para apreciar em Sakara, mas infelizmente raríssimos grupos se deslocam às vizinhas necrópoles para animais sagrados, como o Anubium (preparado para receber as múmias de cães sagrados de Anúbis), o Bubasteum (com milhares de múmias de gatos que evocam a terna deusa Bastet) e o Serapeum (grandes catacumbas dos bois Ápis, animais sagrados do deus Ptah), e, mais lamentável ainda, à grande mastaba do alto funcionário Ti (visitada por Eça de Queirós em 1869). A verdade é que não há tempo para visitar tudo, e isso obriga a uma selecção criteriosa do muito que há para ver.

Seguiu-se a área de Mênfis, uma das mais ricas em vestígios de todas as épocas, na capital da antiga $1 .^{a}$ província do Baixo Egipto, capital política durante o Império Antigo, e capital religiosa e cultural ao longo de toda a história do Egipto, continuando preponderante na dinastia ptolemaica, mau grado a importância de Alexandria. Do que existe no local ressalta a estatuária de Ramsés II, nomeadamente um colosso que jaz deitado num edifício construído para o efeito, e uma esfinge que poderá representar Amen-hotep II, ou, segundo outras hipóteses, a célebre rainha Hatchepsut.

A tarde deste dia 6 foi dedicado à Cidadela de Saladino, a leste da grande metrópole cairota, onde pontifica a mesquita de Mohammed Ali, erigida na primeira metade do século XIX seguindo modelos da otomana Istambul, e onde se encontra o túmulo desse fundador do Egipto moderno. 


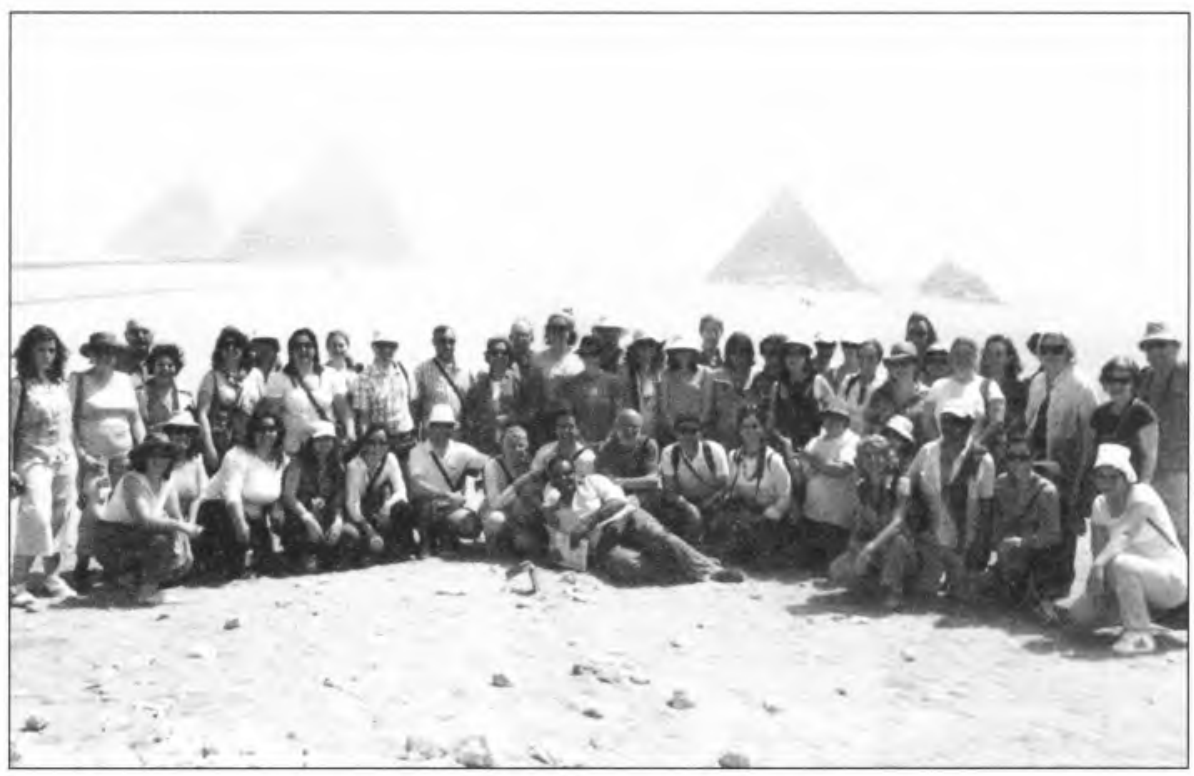

O grupo no planalto de Guiza, com as célebres pirâmides ao fundo.

A excursão a Alexandria decorreu no dia 7 , com partida cedo do Cairo, para na grande urbe mediterrânica serem visitadas as catacumbas de Kom Chugafa, que datam do período romano, com relevo para os vestígios dos séculos II-III d. C., seguindo-se a fortaleza de Qaitbay, no lugar onde antigamente se situava o conhecido farol erigido no início da dinastia ptolemaica. De tarde deu-se um momento alto do programa, quando foi admirada a nova Biblioteca de Alexandria, permitindo esta moderna e atraente construção evocar a antiga instituição de fama universal, cujas preciosidades literárias se perderiam para sempre.

No dia 8 estavam os participantes em Assuão, a antiga capital sulista da $1^{a}$ província do Alto Egipto, então com o nome de Abu, que os Gregos reinterpretarão depois como Elefantina, onde se encontram, na margem contrária do Nilo, na íngreme escarpa rochosa em frente da moderna cidade de Assuão, os túmulos de alguns dos grandes governadores dessa região nos tempos faraónicos, os quais só podem ser percebidos à distância. Ficou por visitar o renovado Museu Núbio, ficará para uma próxima oportunidade - na verdade não há tempo para ver tudo, mas ainda assim foi possível admirar o impressionante Obelisco Inacabado. 
A ilha de Agilkia, onde se encontram os monumentos trasladados da vizinha ilha de Fila, é um aprazível local situado a sul de Assuão, na zona da primeira catarata do Nilo, e que aparece escrito como Filé, Filae, Filas ou Philae. Na ilha de Fila foi erigido um grande templo à deusa Ísis, hoje em Agilkia, com dois pilones, rodeado por edifícios dedicados a várias divindades egípcias e meroíticas: Hórus, Bés, Hathor, Imhotep, Arensnufis e Mandulis. Entre as construções mais antigas desse sítio figuram as do reinado de Nectanebo I (XXX dinastia), a começar pela grande colunata que antecede o templo de ísis, cujas obras datam em grande parte do período ptolemaico, sobretudo de Ptolemeu II. Das construções do período romano destaca-se um santuário iniciado no reinado de Augusto e parcialmente concluído sob Trajano, sendo, por isso mesmo, conhecido como "santuário de Trajano", que é um dos mais famosos entre os monumentos greco-romanos legados pelo antigo Egipto.

De Assuão foi um salto de barco até Kalabcha, onde existe um templo em bom estado de conservação que foi transferido do seu sítio original, mais a sul, devido ao enchimento do lago Nasser. Foi construído no reinado de Augusto, sendo dedicado ao deus núbio Mandulis, ali bem acompanhado por Osíris e Ísis em sugestiva iconografia. Em frente ao pilone existe um cais e um terraço, de onde a vista é admirável, encontrando-se reerguidos em volta do pequeno templo alguns monumentos de várias épocas, alguns datando da pré-história.

No dia 9 estiveram os viajantes em Abu Simbel, um bem conhecido local situado na Núbia egípcia, a cerca de 270 quilómetros a sul da Grande Barragem de Assuão. Os dois templos rupestres de Abu Simbel foram construídos por Ramsés II (XIX dinastia), devendo parte da sua celebridade à grande operação internacional de salvamento de que foram alvo, sob a liderança da UNESCO, aquando da construção da barragem, encontrando-se hoje a salvo, 60 metros mais elevados e 200 metros mais afastados das águas. O grande templo foi consagrado ao deus Ré-Horakhti e ao faraó Ramsés II, e foi construído por volta do ano 30 do seu reinado (cerca de 1260 a. C.). Exibe uma fachada imponente, com 33 metros de altura e 38 metros de largura, esculpida no maciço rochoso e apresentando a forma de um típico pilone egípcio. Entre as cenas do interior destacam-se as que se referem à batalha de Kadech, vendo-se ainda imagens com a rainha Nefertari. Depois da sala da barca, com uma peanha no centro, acede-se, num típico percurso axial, ao santuário recôndito do templo, onde foram esculpidas quatro estátuas: o deus menfita Ptah, outra o deus tebano Amon-Ré, outra o próprio faraó Ramsés II, e uma quarta o 
deus heliopolitano Ré-Horakhti. Perto, fica um templo rupestre mais pequeno dedicado à deusa Hathor e a Nefertari, provido de uma decoração interna mais simples.

Ainda no dia 9, após o regresso de Abu Simbel, começou o cruzeiro, descendo o rio Nilo no acolhedor barco "Beau Soleil», um autêntico hotel flutuante, que levou, sob as bênçãos de Hapi e de Sobek, os viajantes até ao templo de Kom Ombo, hoje parcialmente destruído, sendo apreciado o invulgar plano arquitectónico duplo desta tardia construção greco-romana. A organização em dupla simetria deve-se ao facto de o templo ser dedicado a Hórus (área a norte) e a Sobek (área a sul), sendo este o vestígio mais expressivo da antiga Nubt (a Ombos grega). As inscrições exibem cartelas com os nomes de alguns soberanos ptolemaicos e de imperadores romanos, tendo os visitantes reparado em três aspectos que se evidenciam no local: o nilómetro, o pequeno santuário hatórico no lado sul e o relevo que exibe vários instrumentos cirúrgicos no muro exterior a leste.

No dia 10, atracado o barco em Edfu, seguiu-se de caleche para o impressionante templo de Hórus, ainda muito bem conservado, a testemunhar a permanência do estilo egípcio na arquitectura religiosa que se preservou sob a dinastia ptolemaica (305-30 a. C.). Poucos resistiram à pose para a fotografia junto da estátua falcónida do deus Hórus, no pátio hipostilo do templo, repetindo o gesto de Calouste Gulbenkian nesse mesmo sítio em 1934 - e que todos os anos milhares de turistas vão repetindo. Nos tempos faraónicos a zona era conhecida por Behedet, sendo a capital da $2^{a}$ província do Alto Egipto. Dignos de nota são os abundantes relevos que cobrem praticamente todas as paredes do templo, incluindo os muros envolventes, sendo de destacar as imagens que recriam a luta entre Hórus e Set, isto é, entre o bem e o mal, merecendo ainda interesse o pequeno mammisi (ou casa do nascimento divino) no exterior do templo.

Nesta noite houve animada festa a bordo, com os participantes vestidos com trajes típicos árabes ou trajes regionais do Egipto, em agradáveis momentos de convívio que muitas fotografias obtidas nessa altura hoje bem documentam.

O dia 11 foi dedicado a Lucsor Ocidental, onde muito há para ver, a começar pelo Vale dos Reis, onde, de acordo com a norma habitualmente seguida, foi possível entrar em três túmulos dessa inóspita e isolada necrópole real: desta vez puderam ser admirados os túmulos de Ramsés III, de Ramsés VI e de Tutmés III, uma singela amostra das seis dezenas de túmulos que lá existem. No entanto, e para quem quis, graças a um pagamento adicional, esteve à disposição 
o pequeno túmulo preparado apressadamente para o jovem e frágil rei Tutankhamon - cujo tesouro espectacular tinha já sido apreciado no Museu Egípcio do Cairo. Seguiu-se, com o sol já bem elevado e ardente, o harmonioso templo funerário da rainha Hatchepsut em Deir el-Bahari, adossado à alta falésia da montanha tebana, onde o exímio arquitecto real Senenmut decidiu incrustar esse monumento digno e majestoso, cuja horizontalidade contrasta com a alta verticalidade da escarpa rochosa, para glória de uma das mais famosas rainhas do antigo Egipto. Aí puderam ser vistos os relevos que lembram, entre outros aspectos, a célebre expedição naval ao exótico país de Punt. No regresso a Lucsor, atravessando o chamado "Vale dos Nobres, e depois de uma breve paragem numa oficina de fabrico de recipientes e de objectos de alabastro, e após se ter circundado o Ramesseum, ainda houve tempo para contemplar os chamados "Colossos de Memnon", duas gigantescas estátuas do faraó Amen-hotep III entronizado - é o que resta do que foi o vasto templo funerário deste faustoso monarca, cujo reinado marca um dos momentos mais altos da milenar cibilização egípcia, e onde actualmente decorrem promissores trabalhos de prospecção.

De tarde, e voltando novamente à margem ocidental, ocorreu a entrada no vasto templo de Medinet Habu, razoavelmente bem conservado na sua parte inicial, ao invés dos espaços internos correspondentes às zonas mais recônditas (sala hipostila, sala da barca e o santuário). Trata-se do templo funerário de Ramsés III, o mais importante rei da XX dinastia e para muitos o último grande faraó do Egipto. Depois de ultrapassada a área fortificada antes do primeiro pilone, a qual lembra uma torre ameada síria (e por isso ela é conhecida por migdol), foram convenientemente analisadas as imagens do pilone e as outras no primeiro pátio, que mostram o rei com os deuses e as deusas que o protegem e Ihe prodigalizam a vida eterna, assumindo notória relevância a presença de Amon-Ré, o «rei dos deuses». Passado o segundo pilone, entra-se no segundo pátio hipostilo, onde temática idêntica se distribui pelas paredes, podendo ainda admirar-se em certos relevos as cores originais que ali se conservam.

No dia 12 mereceram justificada atenção os monumentos da margem oriental, isto é, os templos de Karnak e de Lucsor. A esta cidade davam os antigos Egípcios o nome de Uaset, com o significado de "A Próspera", ou simplesmente Niut, que significa "A Cidade". Ela era, de facto, a cidade por excelência, sendo a capital da 4 . $^{a}$ província do Alto Egipto, e a mais notável urbe do Império Novo - rivali- 
zando, no entanto, com as velhas e prestigiadas cidades de Heliópolis e de Mênfis. Hoje é Lucsor, um nome de origem árabe, que pode ser interpretado como "Os Castelos" (Al-Aksur), não se sabendo porque razão os Gregos the chamaram Tebas. O templo de Karnak, dedicado ao deus Amon, era e continua a ser o maior complexo religioso do antigo Egipto. Tem dez pilones, o que dá bem a medida das suas enormes dimensões, dado que habitualmente os templos egípcios só têm um pilone (por vezes podem ter dois, como sucede no templo de Ísis em Fila-Agilkia, ou no de Medinet Habu). Em Karnak foi a habitual deambulação pelas imensas salas, que se vão sucedendo, até os visitantes desembocarem, dando a volta pela zona limítrofe a leste, na área do lago sagrado do templo. Antes do início da visita houve possibilidade para apreciar uma grande maquete que recria os antigos e vastos espaços do templo, podendo assim ser explicitado, em fugaz antevisão, o percurso que iria ser efectuado. Esta é uma das várias inovações positivas que se notam à entrada dos monumentos, onde, é justo reconhecer, tem havido nos últimos anos um claro esforço para alindar e facilitar os acessos.

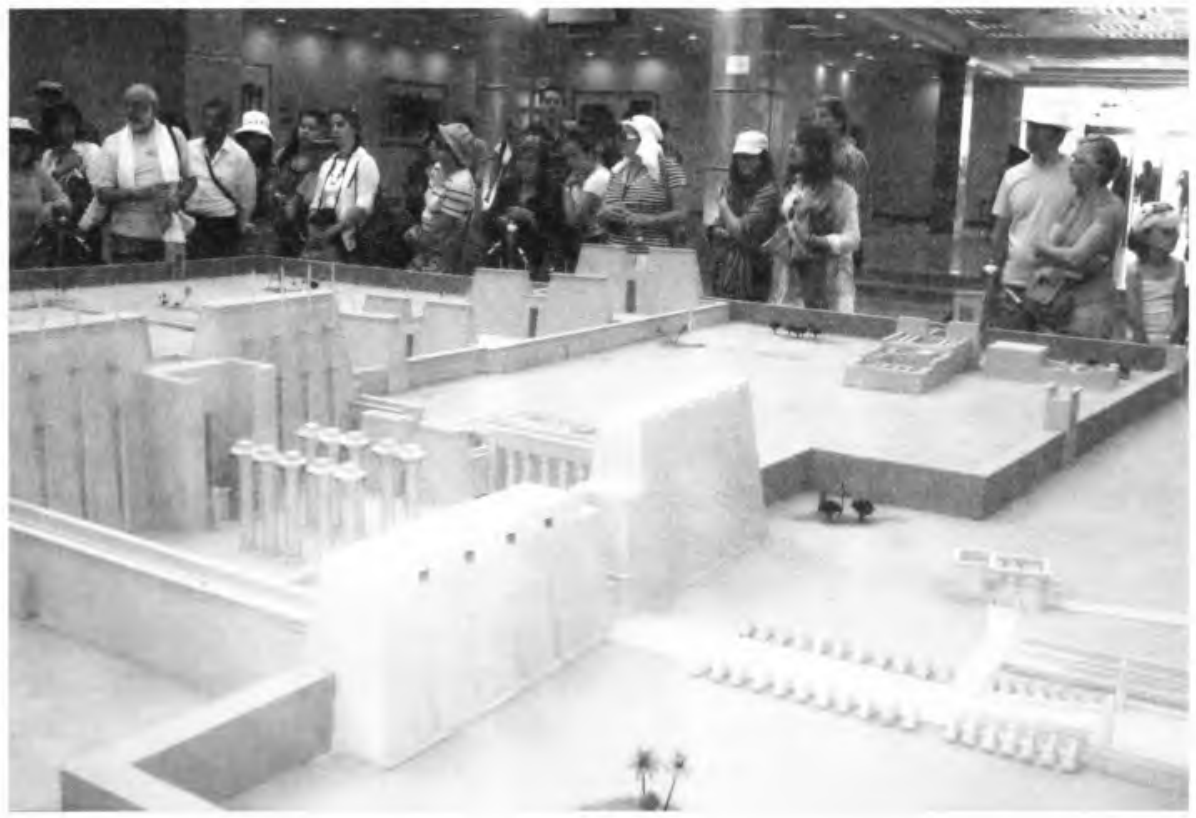

Junto da expressiva maquete pedagógica que mostra o antigo aspecto do templo de Karnak. 
Seguiu-se o templo de Lucsor, considerado nos tempos faraónicos como o "Harém do Sul» (Ipet-resit), obra do Império Novo que se deve sobretudo a dois poderosos monarcas: Amen-hotep III e Ramsés II. Este elegante conjunto de edifícios, que segue o esquema habitual dos complexos templários com o pilone, pátio hipostilo, sala hipostila, sala da barca e santuário, foi erigido junto ao rio Nilo e paralelo a este - a explicação reside no facto de a sua entrada estar virada para o templo de Karnak, mais a norte, sendo a ligação entre os dois estabelecida por uma grande avenida de esfinges que está actualmente em fase de reconstrução. São de notar no templo de Lucsor o pilone de Ramsés II (com cenas alusivas à batalha de Kadech), antecedido por um obelisco (o outro que com ele fazia par está agora em Paris), as elegantes colunas lotiformes do pátio, os relevos que subsistem em algumas paredes, as estátuas colossais, as altas colunas campaniformes de Amen-hotep III, e vários relevos da área coberta, com destaque para as imagens que mostram Alexandre, o Grande, a venerar o deus Amon em itifálica pose mínica.

No dia 13 foi a partida, de autocarro, para Abido e Dendera, alguns quilómetros a norte de Lucsor. A jornada começou por Abido, célebre pelo seu grande templo feito para Osíris, além de muitos outros monumentos dedicados ao senhor da eternidade. Mas Abido, a antiga capital da $8^{a}$ província do Alto Egipto, cujo nome é uma adaptação das antigas formas de Abdju ou Abdu, é sobretudo uma vasta necrópole que abarca todas as épocas da história do Egipto e mesmo da pré e proto-história. São importantes para se conhecer a emergência da nação unificada os túmulos de soberanos da I dinastia e da chamada "dinastia 0". Há ainda catacumbas de cães, íbis e falcões. Existem lá obras de muitos faraós, com especial destaque para os programas de construção levados a cabo por Seti I e seu filho Ramsés II. O principal edifício, com uma invulgar forma em $\mathrm{L}$, foi erigido por Seti I, sendo um templo cenotáfio com belos baixos-relevos pintados. Daqui segue-se para um conjunto subterrâneo conhecido por Osireion (Osireum na forma latina), precedido por uma galeria onde se encontra uma lista com o nome de muitos faraós que antecederam a XIX dinastia, desde o primeiro, Meni (Menés, correspondendo, segundo alguns, a Narmer, ou então a Aha).

De Abido a jornada prosseguiu para Dendera, que se situa à entrada da região tebana, sendo um dos mais conhecidos centros de culto da deusa Hathor. Com o nome egípcio de lunet (Tentyris em grego), era a capital da $6^{a}$ província do Alto Egipto e uma cidade de 
alguma importância, mas desde há muitos séculos que o núcleo da população da área se mudou para Qena, na margem oriental. O complexo do templo de Hathor está agora isolado na extremidade do deserto, tendo sido bem decorado. O edifício tem vários blocos estruturais que revelam que anteriores construções já ali existiram, pois em alguns dos fragmentos lêem-se os nomes de Pepi I (VI dinastia) e de Tutmés III (XVIII dinastia). A grande sala hipostila do templo foi decorada entre os reinados de Augusto e de Nero. Os capitéis têm a forma de um sistro, um instrumento musical sagrado de Hathor, e todas as figuras desses sistros foram severamente mutiladas, talvez por rábidos iconoclastas cristãos. Dentro do templo as partes mais invulgares são as criptas destinadas a guardar as alfaias litúrgicas e os arquivos, e ainda emblemas mágicos para a protecção do edifício. Também há um par de santuários dedicados a Osíris, de um dos quais veio o zodíaco de Dendera, agora no Museu do Louvre. A monumental porta de Domiciano e Trajano conduz a uma área aberta com um mammisi do período romano, situado a oeste. Trata-se do mais recente edifício deste tipo que foi preservado, evocando o ritual onde Hathor dava à luz o jovem deus músico Ihi, que representa a fase jovem de todos os deuses criadores. Uma pequena capela de Nebhepetré Mentuhotep (XI dinastia) foi recuperada do local, e está agora reedificada no Museu Egípcio do Cairo.

$\mathrm{O}$ atraente e muito instrutivo Museu de Lucsor foi visitado no dia 14 , véspera do regresso. O airoso e moderno edifício, dispondo de um circuito expositivo que é um bom modelo de museologia pedagógica, cativou todos os que tiveram ensejo de o percorer, demorando-se na estatuária exposta e nos vestígios do período de Amarna. Quem quis pôde ainda visitar, numa gratificante opção, o impressivo Museu da Mumificação, situado nas proximidades.

No dia 15, pela alvorada, com o sol a romper a custo num céu nublado, chegaram os viajantes a Lisboa, fatigados mas enriquecidos por mais esta jornada cultural levada a efeito pelo Instituto Oriental da Faculdade de Letras da Universidade de Lisboa, e cujo sucesso se deve, em grande medida, à eficaz organização logística proporcionada pela Tui Viagens, cujo relevante profissionalismo se evindencia com toda a justiça.

Luís Manuel de Araújo 